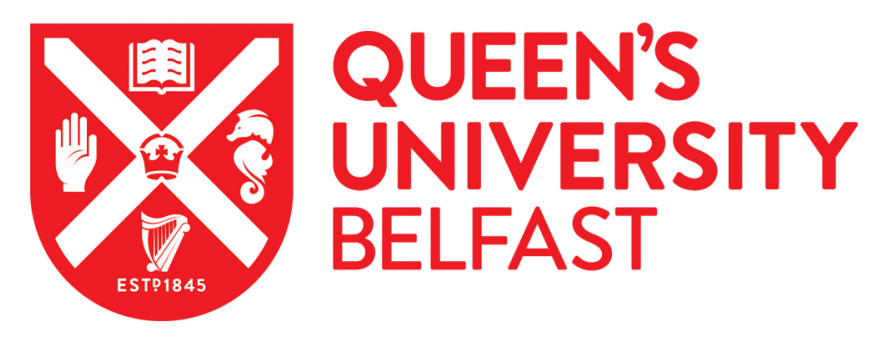

\title{
Operative and radiographic acetabular component orientation in total hip replacement:Influence of pelvic orientation and surgical positioning technique
}

Rutherford, M., O'Connor, J. D., Gill, H. S., Hill, J., Beverland, D., Lennon, A. B., \& Dunne, N. J. (2019). Operative and radiographic acetabular component orientation in total hip replacement:Influence of pelvic orientation and surgical positioning technique. Medical Engineering and Physics.

https://doi.org/10.1016/j.medengphy.2018.12.006

Published in:

Medical Engineering and Physics

Document Version:

Peer reviewed version

Queen's University Belfast - Research Portal:

Link to publication record in Queen's University Belfast Research Portal

\section{Publisher rights}

Copyright 2018 Elsevier.

This manuscript is distributed under a Creative Commons Attribution-NonCommercial-NoDerivs License

(https://creativecommons.org/licenses/by-nc-nd/4.0/), which permits distribution and reproduction for non-commercial purposes, provided the author and source are cited.

\section{General rights}

Copyright for the publications made accessible via the Queen's University Belfast Research Portal is retained by the author(s) and / or other copyright owners and it is a condition of accessing these publications that users recognise and abide by the legal requirements associated with these rights.

Take down policy

The Research Portal is Queen's institutional repository that provides access to Queen's research output. Every effort has been made to ensure that content in the Research Portal does not infringe any person's rights, or applicable UK laws. If you discover content in the

Research Portal that you believe breaches copyright or violates any law, please contact openaccess@qub.ac.uk. 
1 Operative and Radiographic Acetabular Component Orientation in Total Hip

\section{Replacement: Influence of Pelvic Orientation and Surgical Positioning Technique}

Megan Rutherford ${ }^{\mathrm{a}}$, John O’Connor a , Harinderjit Gill ${ }^{\mathrm{b}}$, Janet Hill ${ }^{\mathrm{c}}$, David Beverland ${ }^{\mathrm{c}}$, Alex Lennon ${ }^{a}$, Nicholas Dunne ${ }^{\text {d-h }}$

a School of Mechanical and Aerospace Engineering, Queen’s University of Belfast, Belfast, UK

${ }^{\mathrm{b}}$ Department of Mechanical Engineering, University of Bath, Bath, UK

${ }^{\mathrm{c}}$ Primary Joint Unit, Musgrave Park Hospital, Belfast, UK

${ }^{\mathrm{d}}$ School of Mechanical and Manufacturing Engineering, Dublin City University, Stokes Building, Collins Avenue, Dublin 9, Ireland

${ }^{\text {e }}$ Centre for Medical Engineering Research, School of Mechanical and Manufacturing Engineering, Dublin City University, Stokes Building, Collins Avenue, Dublin 9, Ireland

${ }^{\text {f }}$ School of Pharmacy, Queen’s University Belfast, 97 Lisburn Road, BT9 7BL, UK

g Trinity Centre for Bioengineering, Trinity Biomedical Sciences Institute, Trinity College Dublin, Dublin 2, Ireland

${ }^{\mathrm{h}}$ Department of Mechanical and Manufacturing Engineering, School of Engineering, Trinity College Dublin, Dublin 2, Ireland

\section{Corresponding Author:}

Professor Nicholas Dunne

Centre for Medical Engineering Research,

School of Mechanical and Manufacturing Engineering,

Dublin City University, Stokes Building,

Collins Avenue, Dublin 9, Ireland

nicholas.dunne@dcu.ie

00353 (0) 17005712 
27 Megan Rutherford: Contributed to acquisition, analysis, interpretation of data and drafted the

28

29 paper.

John O’Connor: Critical review and revision of the draft manuscript.

Harinderjit Gill: $\quad$ Critical review of the draft manuscript.

Janet Hill: $\quad$ Contributed to research design, critical review of the draft manuscript, and approval of the submitted manuscript.

David Beverland: Contributed to research design, critical review of the draft manuscript, and approval of the submitted manuscript.

Alex Lennon: $\quad$ Contributed to research design, critical review of the draft manuscript, and approval of the submitted manuscript.

Nicholas Dunne: Contributed to research design, critical review of the draft manuscript, and approval of the submitted manuscript. 


\section{Abstract}

Orthopaedic surgeons often experience a mismatch between perceived intra-operative and radiographic acetabular cup orientation. This research aimed to assess the impact of pelvic orientation and surgical positioning technique on operative and radiographic cup orientation.

Radiographic orientations for two surgical approaches were computationally simulated: a mechanical alignment guide and a transverse acetabular ligament approach, both in combination with different pelvic orientations. Positional errors were defined as the difference between the target radiographic orientation and that achieved.

The transverse acetabular ligament method demonstrated smaller positional errors for radiographic version; $4.0^{\circ} \pm 2.9^{\circ}$ as compared to $9.4^{\circ} \pm 7.3^{\circ}$ for the mechanical alignment guide method. However, both methods resulted in similar errors in radiographic inclination. Multiple regression analysis showed that intraoperative pelvic rotation about the anterior-posterior axis was a strong predictor for these errors $\left(\mathrm{B}_{\mathrm{TAL}}=-0.893, \mathrm{~B}_{\mathrm{MAG}}=-0.951, p<0.01\right)$.

Application of the transverse acetabular ligament method can reduce errors in radiographic version. However, if the orthopaedic surgeon is referencing off the theatre floor to control inclination when operating in lateral decubitus, this is only reliable if the pelvic sagittal plane is horizontal. There is currently no readily available method for ensuring that this is the case during total hip replacement surgery.

Keywords: Pelvic Orientation; Mechanical Alignment Guide; Transverse Acetabular Ligament; Acetabular component inclination 


\subsection{Introduction}

Current survivorship of a primary total hip replacement (THR) exceeds $90 \%$ at ten years [1]. Despite this success, negative outcomes such as dislocation [2] and wear [3] persist. Malalignment of the implanted acetabular component is one factor that has been implicated [3-5]. Great variability in acetabular component orientation is currently observed from post-operative radiographs [6-8]. A number of factors contribute to this variation with the most important being intra-operative pelvic orientation [9-10].

During THR, the acetabular component is inserted into the acetabulum using an introducer. The acetabular component axis is usually co-linear with the handle of the introducer and perpendicular to the face of the acetabular component being inserted. Acetabular component orientation is currently defined in relation to this axis in terms of inclination and version for both the operative and radiographic reference frames [11].

When using a mechanical alignment guide (MAG) in lateral decubitus, the operative inclination is referenced off the theatre floor (as a surrogate for the pelvic sagittal plane) and operative version is referenced from the surgical theatre table longitudinal axis (as a surrogate for the anterior pelvic plane, APP). In reality, the APP is rarely parallel to the patient's coronal plane, and the pelvic sagittal plane may not be parallel to the theatre floor as a result of pre-operative patient positioning and intra-operative pelvic movement [9]. Angles referenced from external theatre landmarks will, therefore, become apparent angles for operative inclination and version. Discrepancies between true (relative to pelvic sagittal plane and APP) and apparent (relative to theatre floor and table) operative acetabular component orientation will contribute to

MAG Mechanical Alignment Guide TAL Transverse Acetabular Ligament APP Anterior Pelvic Plane
A / TOI Apparent / True Operative Inclination

A / TOV Apparent/True Operative Version

NR I/V Neutralised Radiographic Inclination / Version 
inconsistencies between the orthopaedic surgeon's expectations and the reality of post-operative X-ray measurements when using a MAG approach.

The transverse acetabular ligament (TAL) has been used to determine a patient-specific operative version relative to the APP [12]. TAL is independent of patient position but does not provide a solution for operative inclination. To control operative inclination, TAL is often used with a MAG or freehand approach. Pelvic mal-positioning and patient-specific TAL version will contribute to radiographic variability when using this approach.

Post-operatively and intra-operatively there is significant variation in the orientation of the APP with respect to the coronal plane of the patient [13]. This variation is commonly referred to as anterior and posterior pelvic tilt. This tilt, or movement, occurs as a result of flexion or extension of the lumbar spine which results in posterior and anterior tilt of the pelvis respectively. Because the X-ray is taken normal to the patient's coronal plane, pelvic tilt impacts the angle of radiographic version and, to a lesser degree, inclination [14]. Previous work [15-19] has analysed the discrepancy between the 3D orientation (operative or CT) and radiographic orientation of the acetabular component relative to the pelvis. However, the influence of surgical approach has not been explicitly analysed in relation to operative and radiographic acetabular cup orientation.

The aim of this research was to assess the impact of surgical positioning technique on operative and radiographic cup orientation for different pelvic orientations. Two different surgical techniques were simulated using the theory of rigid body transformations. The first used the surgical theatre table longitudinal axis to control operative version. This is equivalent to using the "version guide" on a MAG. The second simulated surgical technique used the TAL. For operative inclination, both techniques used the theatre floor. These approaches are the most commonly adopted within the UK with more than $50 \%$ of orthopaedic surgeons using them 
during THR [20]. Our hypothesis was that the TAL method would result in better control over acetabular component positioning relative to the pelvis when compared to the MAG method.

\subsection{Method}

\subsection{Defining Acetabular Orientation}

Acetabular orientation has previously been defined by inclination and version for both the operative and radiographic reference frames [11]. However, these definitions fail to take into account pelvic orientation [11]. To account for the impact of pelvic orientation, this paper proposes new definitions (Figures 1-3).

Apparent operative acetabular cup orientation is the orientation of the acetabular component axis relative to external landmarks such as the surgical theatre floor and wall, intra-operatively, as perceived by orthopaedic surgeons. Apparent operative inclination (AOI) was defined as the angle between the acetabular component axis and the surgical theatre floor (Figure 1). Apparent operative version (AOV) was defined as the angle between the acetabular component axis and the surgical theatre table longitudinal axis as projected onto the surgical theatre floor (Figure 2).

True operative acetabular orientation represents the orientation of the acetabular component axis relative to internal pelvic landmarks such as the APP intra-operatively. True operative inclination (TOI) was defined as the angle between the acetabular component axis and the pelvic sagittal plane (Figure 1). True operative version (TOV) was the angle between the acetabular component axis and the APP as projected onto the pelvic sagittal plane (Figure 2).

Radiographic inclination and version are the measurements routinely referenced in practice that do not take into account anterior and posterior pelvic tilt. Radiographic inclination (RI) was calculated as the angle between the pelvic longitudinal axis and the acetabular component axis projected onto the coronal plane (Figure 3) [11]. Radiographic version (RV) was determined 
from the relative sizes of the minor and major diameters [21] of the projected acetabular component face (Figure 3). Neutralised radiographic acetabular component orientation was defined as the radiographic inclination (NRI) and version (NRV) that would result from an Xray for which the pelvis was neutral. Radiographic pelvic neutrality was achieved when the APP was parallel to the coronal plane (Figure 3).

\subsection{Intra-operative Pelvic Orientation}

A Sawbones ${ }^{\mathrm{TM}}$ pelvis (Sawbones Europe AB, Sweden) was surface-scanned using a coordinate measurement machine (Hexagon Global Status CMM 092008, Hexagon Manufacturing Intelligence, UK) equipped with a Renishaw PH10M probe head (Renishaw plc, UK) and Nikon LC50 Laser with Nikon Focus scan software (Nikon Corp., Japan) to produce a high density point cloud, which was converted into a surface mesh using 3D scanning and computer aided design (CAD) software (Rapidform XOR, 3D Systems Inc., USA and PTC Creo, PTC Inc., USA) and imported into MATLAB (2015b, The MathWorks Inc., USA). The pelvic model was initially orientated to match the idealised neutral pelvic orientation for a patient undergoing THR of a left hip in lateral decubitus. Operative pelvic neutrality was achieved when the pelvic APP was parallel to the surgical theatre table longitudinal axis, and the pelvic sagittal plane was parallel to the surgical theatre floor.

Coordinates for the hip joint centre of rotation $\left(\hat{c}_{N}\right.$; COR) relative to a neutral pelvis in the operative reference frame were acquired (Figure 4). Rotation of the neutral pelvis about its three axes (Figure 4) was achieved using Equation 1. Regardless of approach, the rotated position of the hip COR $\left(\hat{c}_{R}\right)$ represents the pivot about which the orthopaedic surgeon orientates the acetabular component. Rotation of the upper (left) hemi-pelvis about its longitudinal axis, $R_{x}\left(\theta_{\text {rot }}\right)$, intra-operatively was regarded as internal $(+) /$ external (-) rotation. Rotation of the upper (left) hemi pelvis about its anterior-posterior axis, $R_{y}\left(\theta_{\text {add }}\right)$, was regarded as abduction 
$(+) /$ adduction (-). Rotation of the pelvis about its transverse axis, $R_{z}\left(\theta_{\text {tilt }}\right)$, intra-operatively was termed anterior (+) / and posterior (-) pelvic tilt.

$\widehat{\boldsymbol{c}}_{\mathrm{R}}=\mathbf{R}_{x}\left(\theta_{\text {rot }}\right) \mathbf{R}_{z}\left(\theta_{\text {add }}\right) \mathbf{R}_{y}\left(\theta_{\text {tilt }}\right) \hat{\boldsymbol{c}}_{\mathrm{N}}$

Eqn. 1

\subsection{Mechanical Alignment Guide Approach}

With the pelvis mal-rotated, the acetabular component axis was angled at $45^{\circ}$ relative to the theatre floor (AOI) and $20^{\circ}$ relative to the long axis of the surgical theatre table as projected onto the surgical theatre floor (AOV) [10,21-22]. This was achieved by rotating the acetabular component relative to the axes of its local coordinate frame $\left(\hat{e}_{1}, \hat{e}_{2}\right.$ and $\hat{e}_{3}$,Figure 4$)$. The surgical error (i.e. the orthopaedic surgeon's ability to achieve their target orientation) when using the MAG approach was also incorporated. The surgical errors for version (SEMAGV, $3 \pm 5^{\circ}$ ) and inclination ( $\mathrm{SE}_{\mathrm{MAGI}},-3 \pm 5^{\circ}$ ) were based on an assumed normal distribution defined by mean and standard deviation error values from an experimental study of surgical accuracy [23]. The resultant position of the acetabular cup axis for the MAG approach ( $\hat{\imath}_{\mathrm{M}}$ ) was obtained using Equation 2, which orientated the introducer such that it matched Murray's definitions for operative acetabular orientation.

$\hat{\boldsymbol{\imath}}_{\mathrm{M}}=\left(\boldsymbol{R}_{\mathrm{y}}\left(-A O V+S E_{M A G V}\right) \boldsymbol{R}_{\mathrm{z}}\left(A O I+S E_{M A G I}\right) \hat{\boldsymbol{e}}_{1}\right)+\hat{\boldsymbol{c}}_{\mathrm{R}}$

Eqn. 2

\subsection{Transverse Acetabular Ligament Approach}

For the TAL approach, a TAL axis was introduced relative to the neutral pelvis ( $\hat{\boldsymbol{t}}_{\mathrm{N}}$; Figure 5$)$.

This axis was assigned a case-specific TAL version (TOV) and surgical error ( $S E_{T A L V}$ ), Equation 3. The location of the TAL axis relative to the mal-rotated intra-operative pelvis $\left(\hat{\boldsymbol{t}}_{\mathrm{R}}\right)$ was obtained using Equation 4.

$\hat{\boldsymbol{t}}_{\mathrm{N}}=\left(\boldsymbol{R}_{\mathrm{y}}\left(-T O V+S E_{T A L V}\right) \hat{\boldsymbol{e}}_{3}\right)+\hat{\boldsymbol{c}}_{\mathrm{N}}$

Eqn. 3

$\hat{\boldsymbol{t}}_{\mathrm{R}}=\mathbf{R}_{\mathrm{x}}\left(\theta_{\text {rot }}\right) \mathbf{R}_{\mathrm{z}}\left(\theta_{\text {add }}\right) \mathbf{R}_{\mathrm{y}}\left(\theta_{\text {tilt }}\right) \hat{\boldsymbol{t}}_{\mathrm{N}}$

Eqn. 4 
With the pelvis and consequently the TAL axis mal-rotated, the acetabular component axis was angled at $45^{\circ}$ relative to the surgical theatre floor (AOI) about the TAL axis. A custom solver, Equation 5, was developed to determine the angle $(\alpha)$ that the acetabular cup axis for the TAL method ( $\hat{\boldsymbol{\imath}}_{\mathrm{T}}$ ) would have to rotate about the $\hat{\boldsymbol{t}}_{\mathrm{R}}$ axis to provide an AOI of $45^{\circ}$, between the introducer and theatre floor $\left(\hat{\boldsymbol{\imath}}_{\mathrm{Txz}}\right.$; Figure 5). Surgical errors for the TAL method (SETALI, $-3 \pm$ $5^{\circ}$, and $\mathrm{SE}_{\mathrm{TALV}}, 0 \pm 7^{\circ}$ ) were based on the findings of Grammatopoulos et al [23]. This in turn provided the resultant intra-operative location of the acetabular cup axis when using the TAL $\operatorname{approach}\left(\hat{\boldsymbol{\imath}}_{\mathrm{T}}\right)$.

$f(\alpha)=\left(A O I+S E_{T A L I}\right)-\cos ^{-1}\left(\hat{\boldsymbol{\imath}}_{\mathrm{T}} \cdot \hat{\boldsymbol{\iota}}_{\mathrm{TXZ}}\right)$

Eqn. 5

\subsection{Analysis}

Measures for apparent operative, true operative, radiographic, and neutralised radiographic acetabular orientation were obtained from the model. Variation in TAL version [24], surgical error [23] and pelvic orientation [9] were incorporated into the models to induce variation in the aforementioned measures. For each factor, normal distributions were fitted to clinical data from the literature and sampled randomly $(n=1,000)$. Since one of the main consequences of suboptimal acetabular cup positioning (dislocation) is relatively rare, a large sample size was required in order to include extreme cases. Radiographic projection was modelled according to Freud et al. [25] with a source-to-image distance of $1 \mathrm{~m}$. For repeatability, the source was aligned with the pubic symphysis of the pelvic model whilst the rearmost portion of the pelvic model was aligned with the image plane. As the rearmost portion of the pelvis is aligned with the image plane (supported by the table in practice), if the pelvic tilt changes, the distance between the pubic symphysis and the source would change (as would occur in surgical practice). Therefore there is not a single fixed distance between the pelvis and the source. Target radiographic orientation was the neutralised radiographic orientation that would have been achieved if the 
acetabular component had been implanted into a neutral pelvis intra-operatively in the absence of surgeon error. A case was classified as on-target if its neutralised radiographic orientation was within $10^{\circ}$ of the target radiographic orientation, based on ranges presented by Lewinnek et al [21]. For each case, a positional error was calculated. This was defined as the difference between the neutralised radiographic orientation achieved and the target radiographic orientation. Multiple linear regression, general mixed models, and Chi Square analyses were conducted using SPSS (v22, IBM, USA). Multiple linear regression was used to determine the relationship between positional errors and surgical factors. General mixed models with Bonferroni post-hoc analysis were used to test for statistical differences between measures of orientation. Chi Square analysis was conducted to determine if there was a significant interaction between safe placement and the choice of guidance technique. Further analysis was conducted using the Statistics Toolbox and plotting capabilities within MATLAB® (2015b, The Mathworks Inc., USA). A pvalue of 0.05 was considered significant.

\subsection{Results}

\subsection{Inclination}

No statistical difference ( $p=0.243$ ) was observed between the TAL and MAG methods across the measures of inclination (Figure 6). However, each of the four measures for inclination were mutually statistically different from each other $(p<0.001)$. Despite statistical significance, there was negligible difference between the mean AOI and TOI (MAG $=0.5^{\circ}$, TAL $=0.8^{\circ}$; Table 1 ). The same was true of the difference between the mean RI and NRI $\left(M A G=1.1^{\circ}\right.$, TAL $=1.1^{\circ}$ ).

Regardless of the small deviation in the mean angle of inclination across all measures, there was an initial increase in the ranges between AOI $\left(\Delta \mathrm{AOI}_{\mathrm{MAG}}=20.4^{\circ}, \Delta \mathrm{AOI}_{\mathrm{TAL}}=20.4^{\circ}\right)$ and $\mathrm{TOI}$ groups $\left(\Delta \mathrm{TOI}_{\mathrm{MAG}}=40.9^{\circ}, \Delta \mathrm{TOI}_{\mathrm{TAL}}=45.2^{\circ}\right)$. Despite an orthopaedic surgeon's level of control over the orientation of the introducer relative to the surgical theatre floor, these results indicate 
that intra-operative pelvic orientation can double the range in inclination that an orthopaedic surgeon would expect to see post-operatively.

\subsection{Version}

Unlike inclination, a statistical difference $(p<0.001)$ was observed between the TAL and MAG methods across measures of version (Figure 7). For AOV, the MAG method exhibited tighter control $\left(\triangle \mathrm{AOV} \mathrm{VAG}_{\mathrm{MA}}=21.7^{\circ}\right)$ when compared to the TAL method $\left(\Delta \mathrm{AOV}_{\mathrm{TAL}}=106.7^{\circ}\right)$. Despite this apparent increase in control, the TAL method $\left(\Delta \mathrm{TOV}_{\mathrm{TAL}}=50.1^{\circ}\right)$ results in a smaller range of TOV when compared to the MAG method $\left(\Delta \mathrm{TOV}_{\mathrm{MAG}}=103.2^{\circ}\right)$. Linear regression showed the variability in TOV is predominantly accounted for by the variation in the natural target TAL version ( $r=0.75, p<0.01$ ). From the orthopaedic surgeon's perspective, the angular orientation of the acetabular component may appear excessive when using the TAL method. However, as indicated by the reduction in TOV over AOV, the TAL method results in better control over operative version.

AOV and TOV were considered statistically similar $(p=0.243)$, while the other measures were all mutually statistically different $(p<0.001)$. The introduction of anterior and posterior pelvic tilt alters the angle of version projected onto the coronal plane, accounting for differences between the operative measures of version and the radiographic version. Deviations between the mean TOV $\left(\mathrm{MAG}=16.5^{\circ}, \mathrm{TAL}=17.9^{\circ}\right)$ and the mean NRV $\left(\mathrm{MAG}=8.82^{\circ}, \mathrm{TAL}=10.1^{\circ}\right)$ reflect the inadequacy of the ellipse fitting method used to compute the three-dimensional version of the acetabular component from a two-dimensional radiograph.

\subsection{Positional Errors}

Target radiographic inclination and version for the MAG method was $47.8^{\circ}$ and $10.6^{\circ}$ respectively when aiming for $45^{\circ}$ of operative inclination and $20^{\circ}$ of operative version. Due to 
the natural variation in TAL-based version, target radiographic inclination and version were case-specific for the TAL method even though target operative inclination was constant. Mean target radiographic inclination for the TAL method was $47.8^{\circ}\left( \pm 1.52^{\circ}, \min =45.1^{\circ}\right.$, $\left.\max =52.2^{\circ}\right)$. Mean target radiographic version for the TAL method was $9.96^{\circ}\left( \pm 4.46^{\circ}, \min =0.02^{\circ}, \max =\right.$ $\left.20.1^{\circ}\right)$. Target radiographic inclination $(n=104 / 1,000)$ and radiographic version $(n=148 / 1,000)$ for a number of TAL cases fell outside of the Lewinnek target zone ${ }^{20}$ (Figures 6 and 7). Thus, acetabular components may be classified as unsafe when using the Lewinnek target zone, despite being placed inside the allowable margin of error $\left( \pm 10^{\circ}\right)$ relative to their intended orientation.

A Chi-square test of independence was calculated comparing the frequency of acetabular components placed safely when using the TAL and MAG method. A significant interaction was found $\left(\chi^{2}(1, \mathrm{n}=1,000)=150.3, \mathrm{p}<0.01\right)$ between insertion methods and safe placement. With respect to placement within the safe zones for both radiological inclination and version, the TAL method $(n=778 / 1,000)$ exhibited a 33.7\% increase in safe placement over the MAG method (n $=516 / 1,000)$.

For inclination error (Figure 8, Table 2), multivariate linear regression showed that the strongest standardised coefficients (B), or predictors, were the orthopaedic surgeon's ability to achieve their desired target angle $\left(\mathrm{B}_{\mathrm{MAG}}=1.02, \mathrm{~B}_{\mathrm{TAL}}=1.10, p<0.01\right)$ and intra-operative control of pelvic adduction $\left(\mathrm{B}_{\mathrm{MAG}}=-0.95, \mathrm{~B}_{\mathrm{TAL}}=-0.89, p<0.01\right.$ ) for both MAG and TAL (Figure 8, Table 2). For errors in version, the orthopaedic surgeon's ability to achieve their desired target angle $\left(\mathrm{B}_{\mathrm{MAG}}=0.711, p<0.01\right)$ and intra-operative control of pelvic flexion were the strongest predictors $\left(\mathrm{B}_{\mathrm{MAG}}=0.689, p<0.01\right)$ for MAG. For TAL, only the orthopaedic surgeon's ability to achieve their desired target angle $\left(\mathrm{B}_{\mathrm{TAL}}=0.708, p<0.01\right)$ was a notable predictor of version error. 


\subsection{Discussion}

We hypothesised that the TAL method would result in better control over acetabular component positioning relative to the pelvis when compared to the MAG method. The TAL method ( $\Delta \mathrm{TOV}$ $\left.=50.0^{\circ}\right)$ resulted in a smaller range of TOV when compared to the MAG method $(\Delta \mathrm{TOV}=$ $\left.103.2^{\circ}\right)$. However, for TOI, the TAL method $\left(\Delta \mathrm{TOI}=45.3^{\circ}\right)$ exhibited similar variability to the MAG method $\left(\Delta \mathrm{TOI}=41.0^{\circ}\right)$. The TAL method uses a fixed internal patient-specific landmark for controlling operative version, which can counteract changes in pelvic tilt. However, as with the MAG method, it relies on the fixed external surgical theatre floor for controlling operative inclination. Overall, our hypothesis that the TAL method would lead to better control over acetabular component orientation was supported by the results herein.

For both methods, intra-operative pelvic orientation at least doubled the range in inclination that an orthopaedic surgeon would expect to see post-operatively. This is particularly influenced by pelvic adduction. However, high natural cup version combined with internal rotation can also be a contributing factor. Therefore, in lateral decubitus, the surgical theatre floor can only be used as a reliable landmark for operative inclination if the sagittal plane of the pelvis is horizontal.

Meermans et al. ${ }^{26}$ conducted a clinical trial comparing the TAL and freehand techniques. From their findings, the TAL method was better at controlling radiological version than the MAG technique, which concurs with the findings from this study. The range in measured radiological version obtained using our theoretical model (MAG: $-35.5^{\circ}$ to $37.4^{\circ}$, TAL: $-24.4^{\circ}$ to $30.1^{\circ}$ ) differs from that obtained by Meermans et al in a clinical setting (MAG: $2^{\circ}$ to $35^{\circ}$, $\mathrm{TAL}: 2^{\circ}$ to $25^{\circ}$ ). An advantage of the theoretical model is the spatial location of the acetabular component axis relative to the radiographic coronal plane is known. This enables differentiation between retroverted and anteverted acetabular components, which is not possible on the AP X-ray. Ignoring the possibility of retroversion by taking the absolute values of measured radiographic 
version only, the ranges obtained from the theoretical model (MAG: $0^{\circ}$ to $37.4^{\circ}$, TAL: $0^{\circ}$ to $30.1^{\circ}$ ) concurs with data reported by Meermans et al [26].

Meermans et al. [26] concluded that the TAL method was better at controlling radiological version based upon their radiographic outcomes being within the Lewinnek target zone. ${ }^{21}$ Natural variation of TAL, [23] along with the natural variation in pelvic tilt, [13] may result in greater inter-patient variability with respect to measured radiological version. In this study, patientspecific targets for NRI and NRV were calculated. With respect to the Lewinnek target zone [21], 43\% ( $n=430 / 1000)$ of target neutralised radiographic orientations fell outside for TAL. Other studies have also noted potential problems with using global, rather than patient-specific, targets; e.g. Abdel et al. [6] illustrated that $58 \%$ of dislocations from their prospective study were located within the Lewinnek target (safe) zone. To date, no consensus regarding safe orientation of the acetabular component exists [2,8,27]. Irrespective of the safe zone used to assess radiographic success post-operatively, TAL has been associated with a reduced rate of dislocation [12]. ${ }^{12}$

A potential limitation of this study is the use of a single order of rotations. However, the same pelvic orientation can result from differently ordered rotations. Thus, changing the order of the rotations only varies the mapping procedure required to gain a particular pelvic orientation. If we were to include multiple mappings, duplicate pelvic positions would result, which may bias the data and subsequent observations from this study. A limitation of the theoretical model was that it was based on clinical data from a limited number of institutions [9,23,24]. For example, the extent of pelvic mal-positioning may be influenced by the type of intraoperative patient support. Additionally, in practice, an orthopaedic surgeon will be able to use their experience to avoid extreme orientations that are not accounted for in the model. This study was performed on a single, representative pelvic shape. Since the key variables are angles (as opposed to lengths), 
we expect that data and study observations will apply to a wide variation of pelvic shapes. However, this has not been analysed here and these methods could be applied in future studies.

Computer Aided Orthopaedic Surgery (CAOS) has been shown to reduce the variance in acetabular component placement ${ }^{28}$ by determining the intra-operative pelvic orientation. This is most accurately achieved using an image-based system that recognises the internal anatomy during THR surgery and then builds a three-dimensional image of the pelvis from this. In contrast, image-free systems are more widely used to build a three-dimensional image by referencing bony landmarks on the pelvis through skin, which in turn introduces errors. ${ }^{29}$ Within the United Kingdom, CAOS is used in less than 1\% of THR surgeries [30]. This may be due to cost, increased operative time, and lack of published benefit [31,32]. For example, Lass et al. [33] illustrated no significant difference between the MAG method and an image free system for controlling TOI.

\subsection{Conclusion}

In this study, which simulated two different surgical techniques, the TAL method exhibited greater control over radiographic version and placed 33.7\% more acetabular components in the hypothetical target zone when compared to the application of the MAG method. However, with respect to inclination, both the TAL and MAG methods performed poorly when the sagittal pelvic plane was not parallel to the surgical theatre floor. Consequently, there is an imperative to find an affordable and practical method to ensure the sagittal plane of the pelvis is parallel to the surgical theatre floor at the time of acetabular component insertion. 
345 There are no conflicts of interest.

\section{$346 \quad$ Funding}

347 M. Rutherford would like to acknowledge the financial support of the Belfast Arthroplasty

348 Research Trust for this study. D. E. Beverland has stated that he, along with the Belfast Health 349 and Social Care Trust, has received funding from Depuy Synthes for this study.

\section{Ethical approval}

351 No ethical approval was required for this study. 


\section{References}

354 [1] Kim Y, Park J, Kim J, Kim I. Twenty five to twenty seven year results of a cemented vs a 355 cementless stem in the same patients younger than 50 years of age. J Arthroplasty 2016; 31(3): 356 $662-7$.

357 [2] Biedermann R, Tonin A, Krismer M, Rachbauer F, Eibl G, Stöckl B. Reducing the risk of dislocation after total hip arthroplasty: The effect of orientation of the acetabular component. Bone Joint J 2005; 87-B(6):762-9.

[3] Wan Z, Boutary M, Dorr LD. The influence of acetabular component position on wear in 361 total hip arthroplasty. J Arthroplasty 2008; 23(1):51-6.

[4] Little N, Busch C, Gallagher J, Rorabeck CH, Bourne RB. Acetabular polyethylene wear and 363 acetabular inclination and femoral offset. Clin Orthop Relat Res 2009; 467(11):2895-2900.

[5] von Knoch M, Berry DJ, Harmsen WS, Morrey BF. Late dislocation after total hip arthroplasty. J Bone Joint Surg Am 2002; 84-A(11):1949-53.

[6] Abdel M, Roth P, Jennings M, Hanssen AD, Pagnano MW. What safe zone? The vast majority of dislocated THAs are within the Lewinnek safe zone for acetabular component position. Clin Orthop Relat Res 2015; 474(2):386-91.

369 [7] Langton DJ, Joyce TJ, Jameson SS, Lord J, Van Orsouw M, Holland JP et al. Adverse reaction to metal debris following hip resurfacing. J Bone Joint Surg Br 2011; 93-B(2):164-71.

371 [8] Danoff JR, Bobman JT, Cunn G, Murtaugh T, Gorroochurn P, Geller JA et al. Redefining 372 the acetabular component safe zone for posterior approach total hip arthroplasty. J Arthroplasty 373 2016; 31(2):506-511. 
[9] Grammatopoulos G, Pandit HG, da Assunção R, Taylor A, McLardy-Smith P, De Smet KA et al. Pelvic position and movement during hip replacement. Bone Joint J 2014; 96-B(7):876883.

[10] Beverland DE, O'Neill CK, Rutherford M, Molloy D, Hill JC. Placement of the acetabular component. Bone Joint J 2016;98-B (1 Supple A):37-43.

[11] Murray DW. The definition and measurement of acetabular orientation. J Bone Joint Surg $\operatorname{Br} 1993 ; 75-B(2): 228-32$.

[12] Archbold HA, Mockford B, Molloy D, McConway J, Ogonda L, Beverland D. The transverse acetabular ligament: An aid to orientation of the acetabular component during primary total hip replacement: A preliminary study of 1000 cases investigating postoperative stability. J Bone Joint Surg Br 2006;88-B(7):883-6.

[13] Murphy WS, Klingenstein G, Murphy SB, Zheng G. Pelvic tilt is minimally changed by total hip arthroplasty. Clin Orthop Relat Res 2013; 471(2):417.

[14] Haenle M, Heitner A, Mittelmeier W. Assessment of cup position from plain radiographs: Impact of pelvic tilting. Surg Radiol Anat 2007; 29(1):29-35.

[15] Grammatopoulos, G, Pandit HG, da Assunção R, McLardy-Smith P, De Smet KA, Gill HS et al. The relationship between operative and radiographic acetabular component orientation: Which factors influence resultant cup orientation? Bone Joint J 2014; 96-B(10), 1290-7 .

[16] Davda K, Smyth N, Cobb JP \& Hart AJ. 2D measurements of cup orientation are less reliable than 3D measurements: A retrospective study of 87 metal-on-metal hips. Acta Orthop 2015; 86(4): 485-490. 
[17] Wassilew GI, Heller MO, Diederichs G, Janz V, Wenzl M, Perka C. Standardized AP radiographs do not provide reliable diagnostic measures for the assessment of acetabular retroversion. J Orthop Res 2012; 30(9):1369-76.

[18] Schwarz TJ, Weber M, Dornia C, Worlicek M, Renkawitz T, Grifka J et al. Correction of Pelvic Tilt and Pelvic Rotation in Cup Measurement after THA - An Experimental Study. Rofo 2017;189(9):864-73.

[19] Derbyshire B. Correction of acetabular cup orientation measurements for X-ray beam offset. Med Eng Phys 2008; 30(9):1119-26.

[20] Rutherford M, O'Connor JD, Hill JC, Beverland DE, Lennon AB, Dunne NJ. Patient positioning and cup orientation during total hip arthroplasty: assessment of current UK practice. Hip International 2018; [Epub ahead of print].

[21] Lewinnek G, Lewis J, Tarr R, Compere CL, Zimmerman JR. Dislocations after total hipreplacement arthroplasties. J Bone Joint Surg 1978; 60(2):217-220.

[22] Barrack, R. L. Dislocation after total hip arthroplasty: implant design and orientation. J Am Acad Orthop Surg 2003; 11(2): 89-99.

[23] Grammatopoulos G, Alvand A, Monk AP, Mellon S, Pandit H, Rees J, Gill HS, Murray DW. 2016. Surgeons’ Accuracy in Achieving Their Desired Acetabular Component Orientation. Bone Joint J 98-A(17): 72.

[24] Merle C, Grammatopoulos G, Waldstein W, Pegg E, Pandit H, Aldinger PR, Gill HS, Murray DW. 2013. Comparison of Native Anatomy with Recommended Safe Component Orientation in Total Hip Arthroplasty for Primary Osteoarthritis. Bone Joint J 95-A(7): 17211727. 
417

418

419

420

421

422

423

424

425

426

427

428

429

430

431

432

433

434

435

436

437

438

[25] Freud N, Duvauchelle P, Létang JM, Babot D. Fast and robust ray casting algorithms for virtual X-ray imaging. Nucl Instruments Methods Phys Res Sect B Beam Interact with Mater Atoms 2006; 248:175-80.

[26] Meermans G, Van Doorn WJ, Koenraadt K, Kats J. The use of the transverse acetabular ligament for determining the orientation of the components in total hip replacement. Bone Joint J 2014; 96-B(3):312-18.

[27] Elkins J, Callaghan J, Brown T. The 'Landing zone' for wear and stability in total hip arthroplasty is smaller than we thought: A computational analysis. Clin Orthop Relat Res 2014; 473(2):441-52.

[28] Digioia III AM, Jaramaz B, Plakseychuk AY, Moody JE Jr, Nikou C, Labarca RS et al. Comparison of a mechanical acetabular alignment guide with computer placement of the socket. J Arthroplasty 2002; 17(3):359-64.

[29] Lin F, Lim D, Wixson RL, Milos S, Hendrix RW, Makhsous M. Limitations of imageless computer-assisted navigation for total hip arthroplasty. J Arthroplasty 2011; 26(4):596-605.

[30] UK National Joint Registry. 10th Annual Report, http://www.njrcentre.org.uk/njrcentre/Portals/0/Documents/England/Reports/10th_annual_repo rt/NJR\%2010th\%20Annual\%20Report\%202013\%20B.pdf; 2013 [Accessed July 1, 2014].

[31] Najarian BC, Kilgore JE, Markel DC. Evaluation of component positioning in primary total hip arthroplasty using an imageless navigation device compared with traditional methods. J Arthroplasty 2009;24(1):15-21.

[32] Sikorski JM, Chauhan S. Computer-assisted orthopaedic surgery: Do we need CAOS? J Bone Joint Surg Br 2003; 85-B(3):319-23. 
439 [33] Lass R, Kubista B, Olischar B, Frantal S, Windhager R, Giurea A. Total hip arthroplasty 440 using imageless computer-assisted hip navigation: A prospective randomized study. J $441 \quad$ Arthroplasty 2014; 29(4):786-91.

442 


\begin{tabular}{|c|c|c|c|c|c|c|c|c|}
\cline { 2 - 9 } & \multicolumn{4}{c|}{ Mechanical Alignment Guide (MAG) } & \multicolumn{3}{c|}{ Transverse Acetabular Ligament (TAL) } \\
\cline { 2 - 10 } & $\begin{array}{c}\text { Min } \\
\text { (degrees) }\end{array}$ & $\begin{array}{c}\text { Max } \\
\text { (degrees) }\end{array}$ & $\begin{array}{c}\text { Mean } \\
\text { (degrees) }\end{array}$ & $\begin{array}{c}\text { SD } \\
\text { (degrees) }\end{array}$ & $\begin{array}{c}\text { Min } \\
\text { (degrees) }\end{array}$ & $\begin{array}{c}\text { Max } \\
\text { (degrees) }\end{array}$ & $\begin{array}{c}\text { Mean } \\
\text { (degrees) }\end{array}$ & $\begin{array}{c}\text { SD } \\
\text { (degrees) }\end{array}$ \\
\hline AOI & 28.6 & 49 & 41.4 & 4.2 & 28.6 & 49 & 41.4 & 4.2 \\
\hline TOI & 22.1 & 63.1 & 41.9 & 7.1 & 19.2 & 64.5 & 42.2 & 7.8 \\
\hline RI & 22.3 & 66.2 & 44.2 & 7.6 & 18.5 & 65.1 & 43.9 & 7.6 \\
\hline NRI & 22.7 & 71.4 & 45.3 & 7.9 & 20.2 & 67.4 & 45 & 7.5 \\
\hline PI* & 0 & 25 & 6.6 & 5 & 0 & 27.6 & 6.4 & 5 \\
\hline AOV & 2.2 & 23.9 & 16.1 & 4.4 & -34.8 & 71.9 & 17.7 & 19 \\
\hline TOV & -40.6 & 62.6 & 16.5 & 16.8 & -8.7 & 41.3 & 17.9 & 9.3 \\
\hline RV & -35.5 & 37.4 & 3.8 & 12.6 & -24.4 & 30.1 & 5.1 & 8.5 \\
\hline NRV & -32.1 & 44 & 8.8 & 11.8 & -9.1 & 35.2 & 10.1 & 7 \\
\hline PV* & 0 & 42.7 & 9.4 & 7.3 & 0 & 17.4 & 4 & 2.9 \\
\hline
\end{tabular}




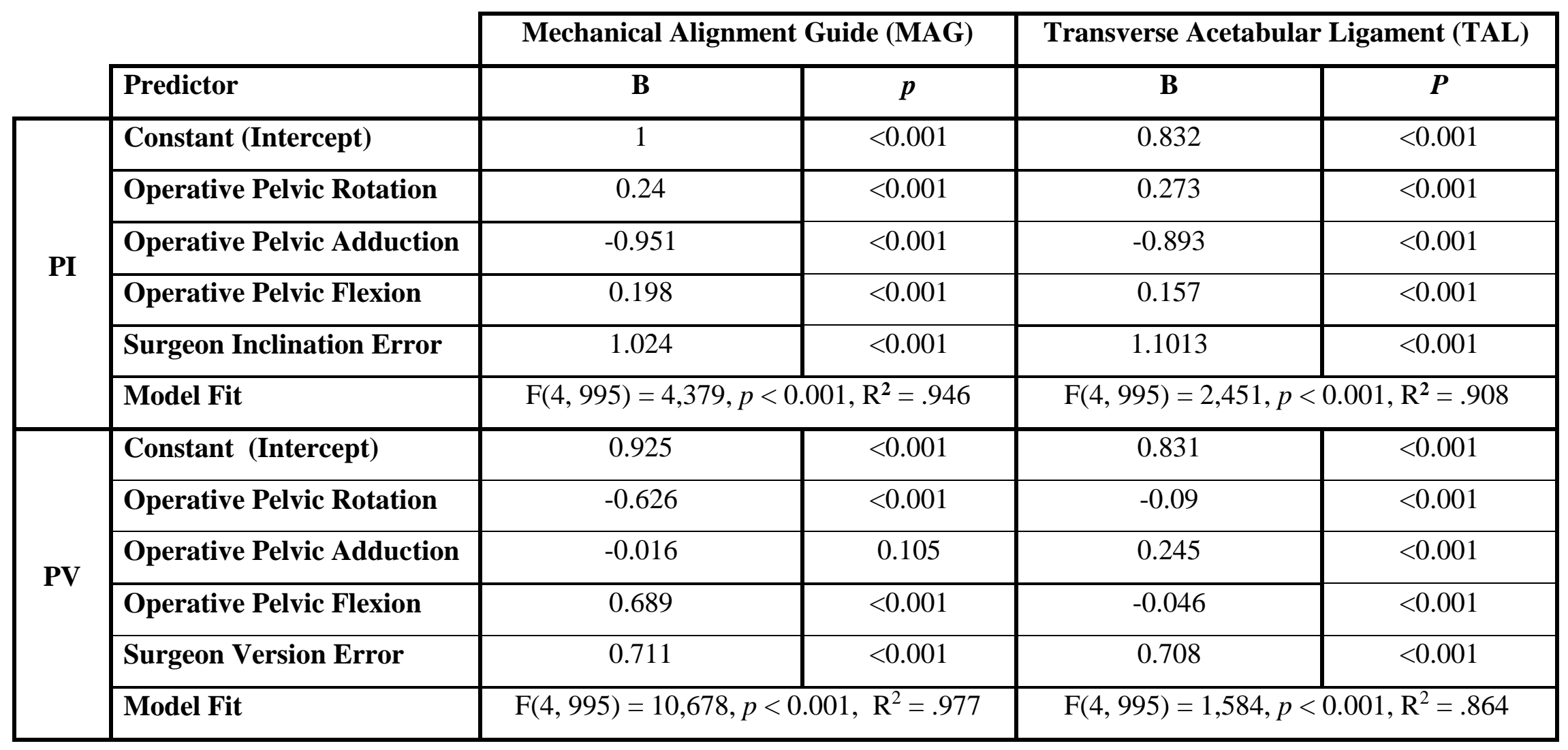


Figures

461

462

463

464

465

466

467

468

469

470

471

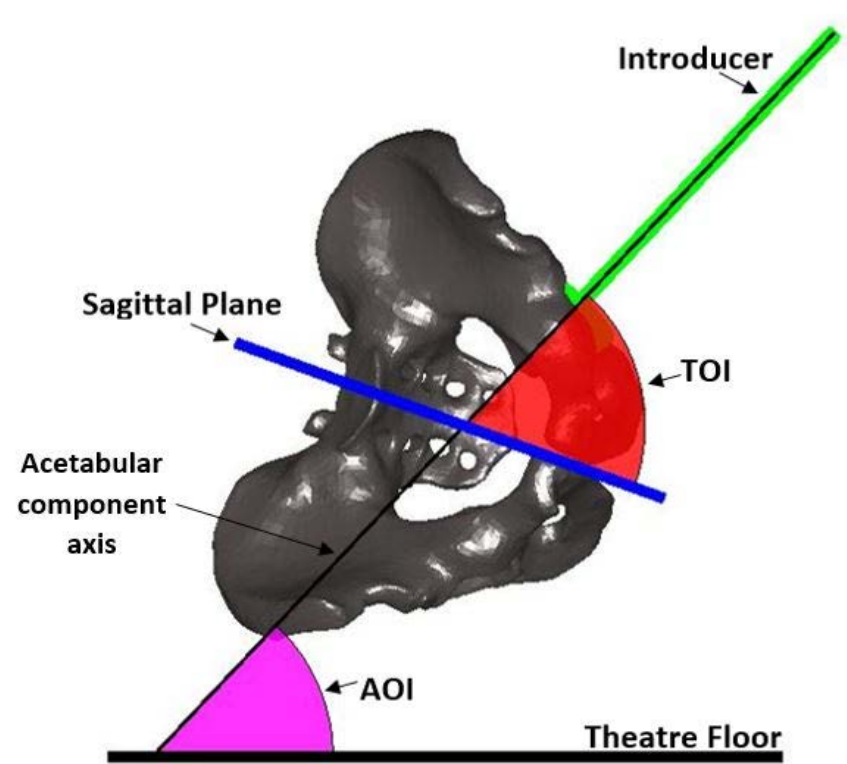

Figure 1: Apparent (AOI) and True Operative Acetabular Inclination (TOI). TOI is the angle between the acetabular component axis and the pelvic sagittal plane. AOI is the angle between the acetabular component axis and the surgical theatre floor. 


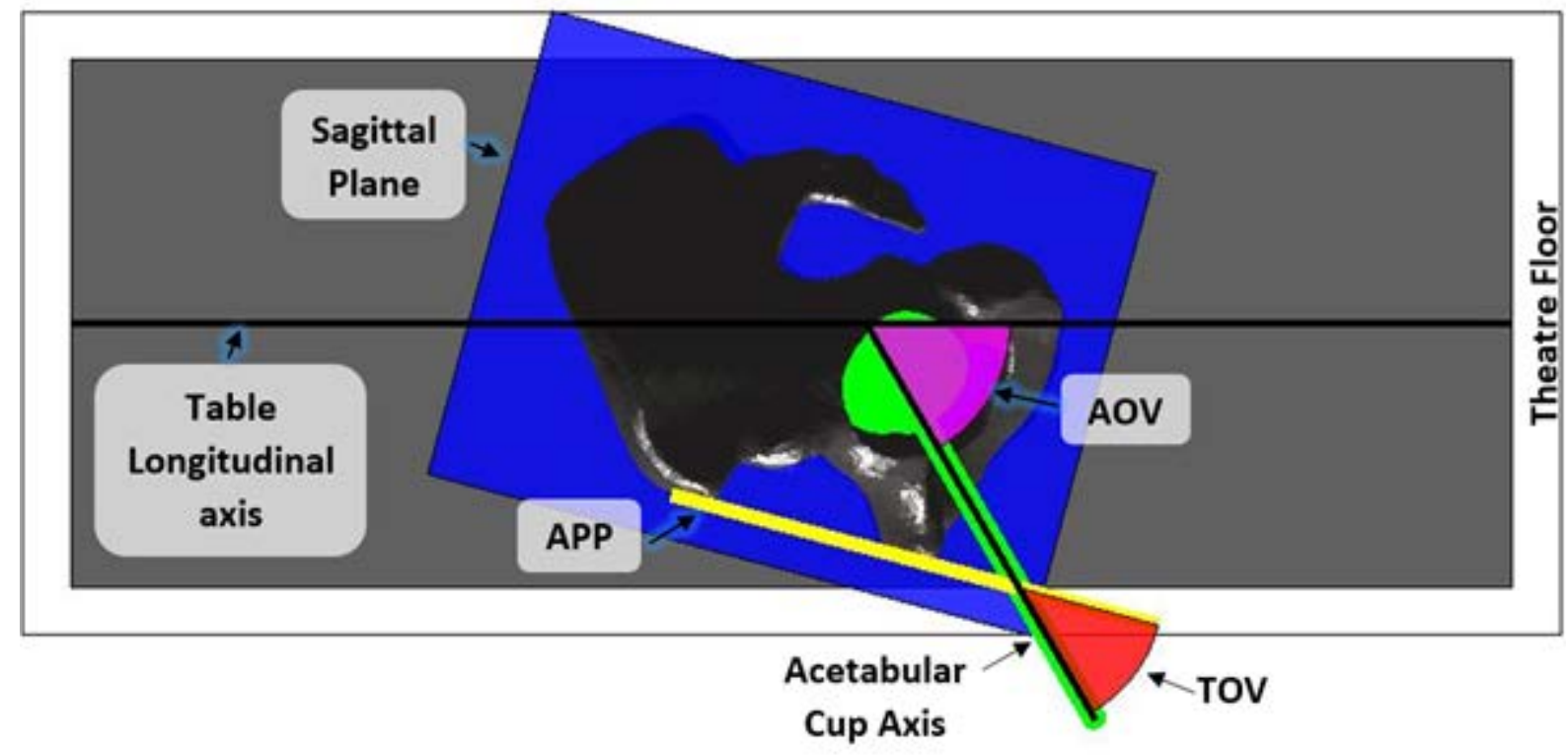

472

473 Figure 2: Apparent (AOV) and True Operative Acetabular Version (TOV). AOV is the angle between acetabular component axis and surgical theatre table longitudinal axis as projected onto the surgical theatre floor. TOV is the angle between the acetabular component axis and anterior pelvic plane (APP) as projected onto the pelvic sagittal plane. 

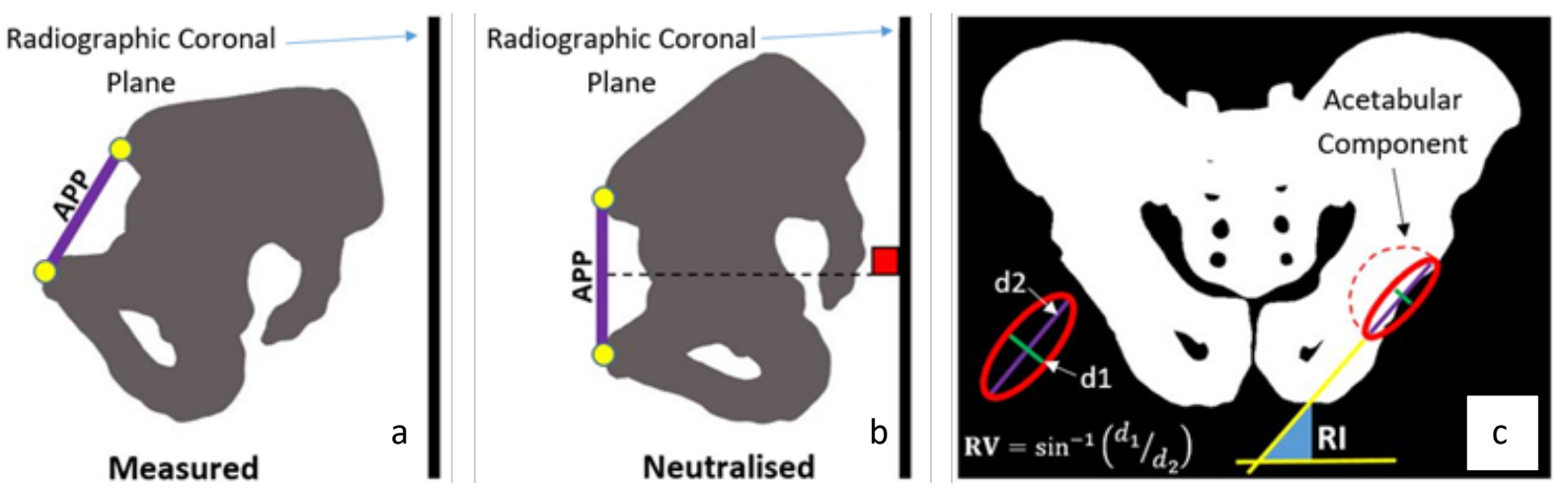

479

Figure 3: Measured and Neutralised Radiographic Measurements: a \& c) radiographic inclination (RI) and Version (RV) are measures of inclination and version taken from an anterior-posterior radiograph for which the orientation of the pelvis has not been accounted for; b \& c) neutralised radiographic inclination (NRI) and version (NRV) are measures of radiographic inclination and version taken from an anterior-posterior radiograph for which the orientation of the pelvis has been accounted for. 

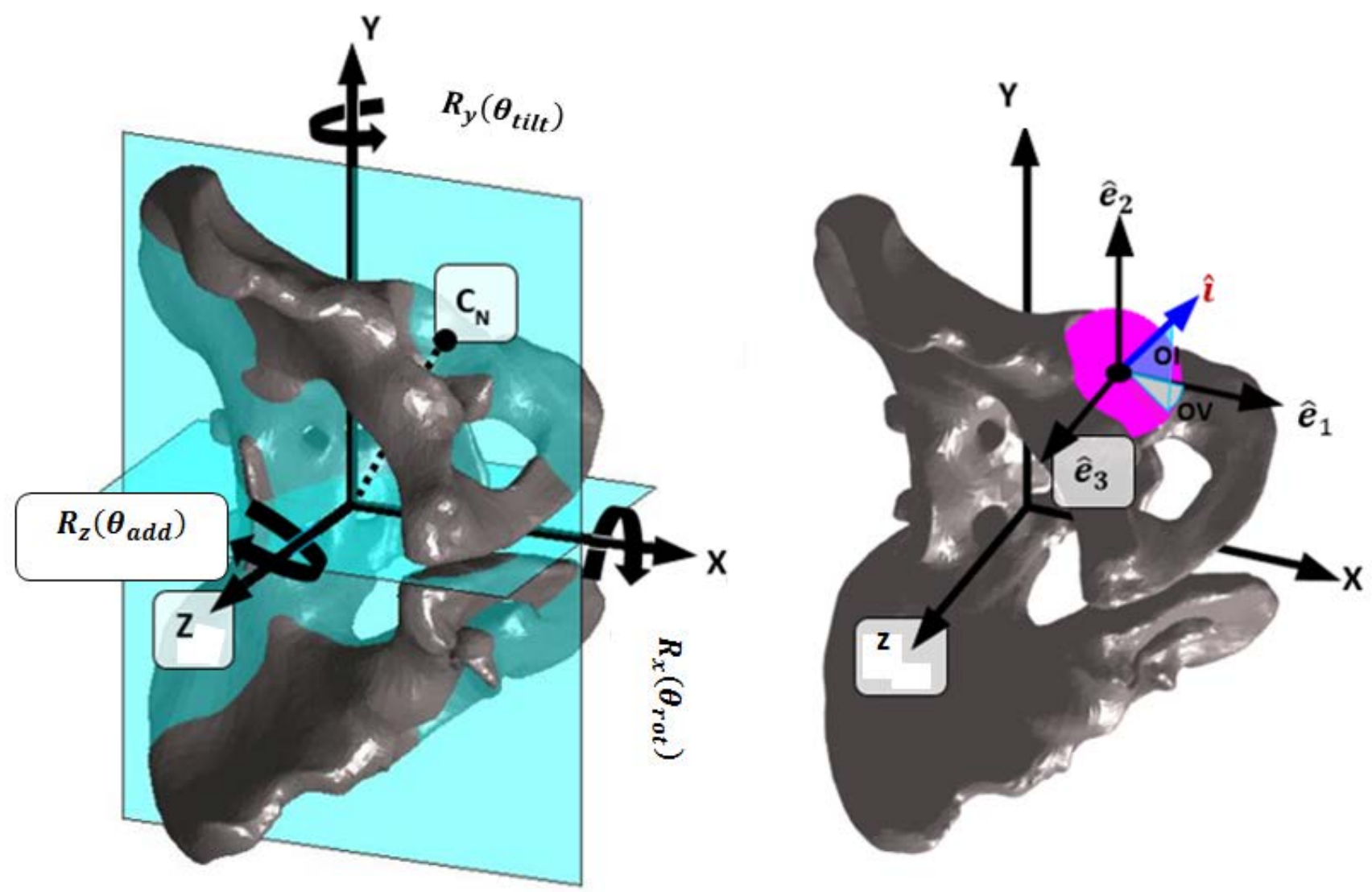


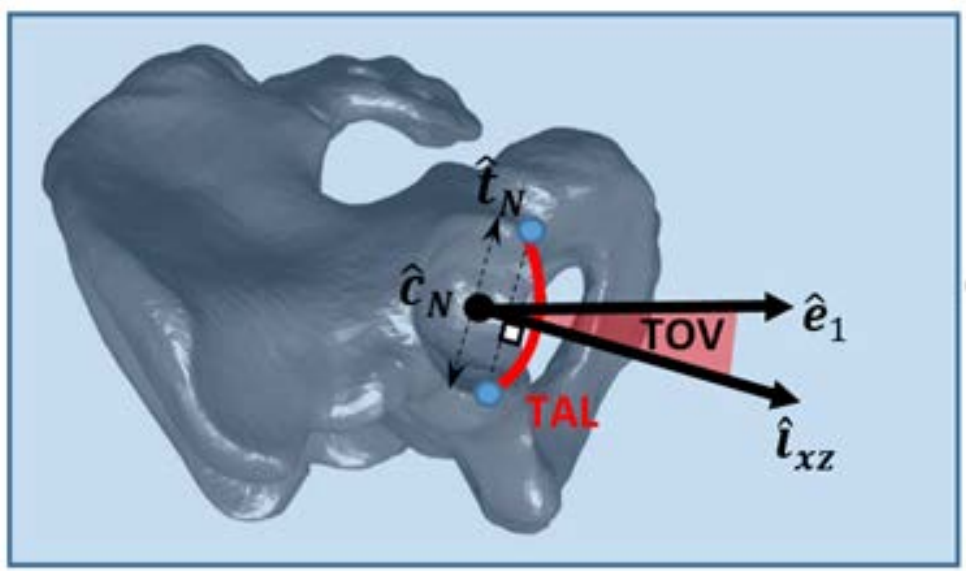

Figure 5: Schematic diagram depicting a neutral transverse acetabular ligament (TAL) axis $\left(\hat{t}_{\mathrm{N}}\right)$ at a case-specific TOV.

496

497

498

499

500

501

502 


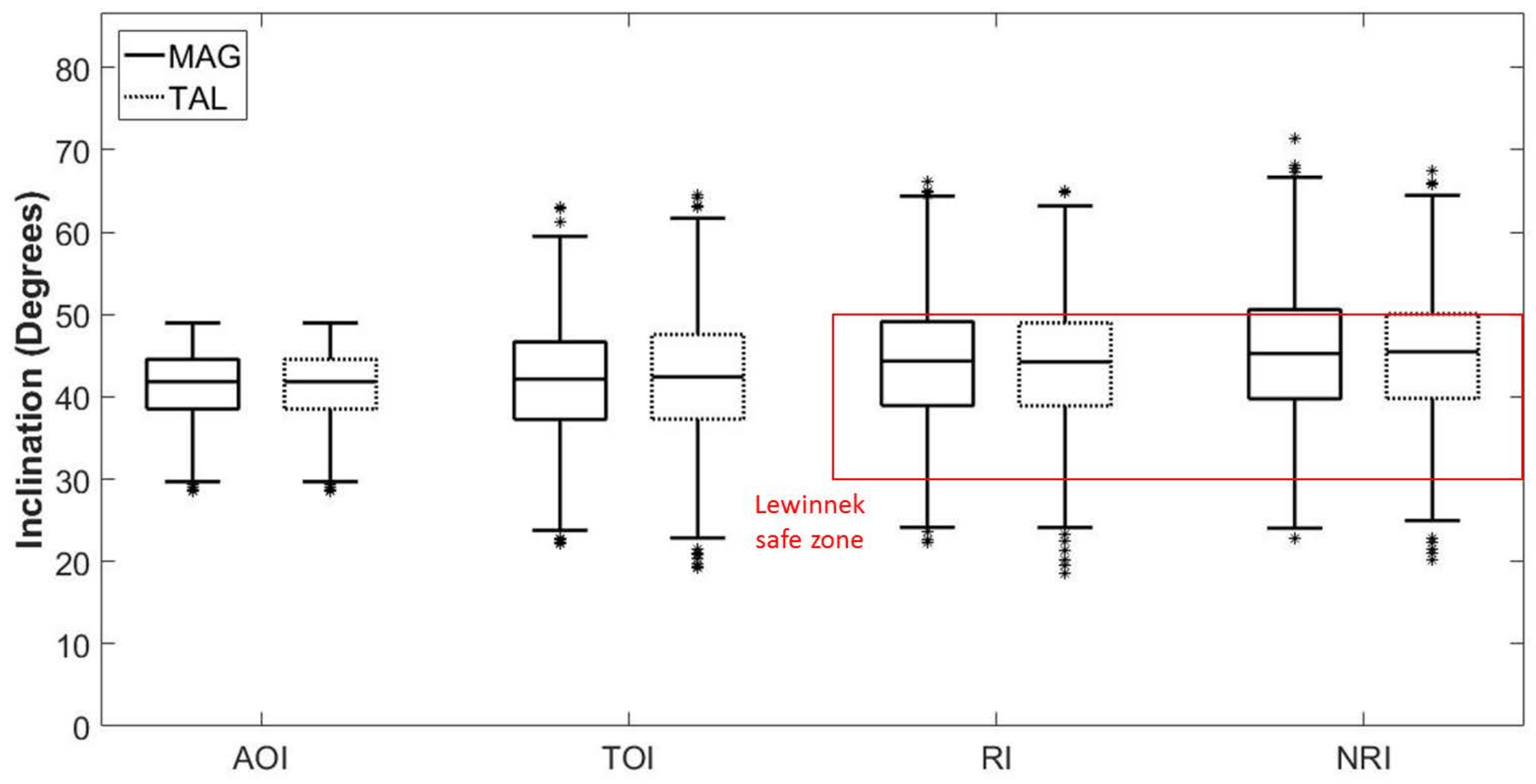

Figure 6: Measures of Inclination. No statistical differences were observed between approaches ( $\mathrm{p}=0.243)$. Both methods exhibit similar control

over TOI. Operative pelvic orientation doubles the range in inclination that an orthopaedic surgeon would expect to see post-operatively. Outliers respectively. 


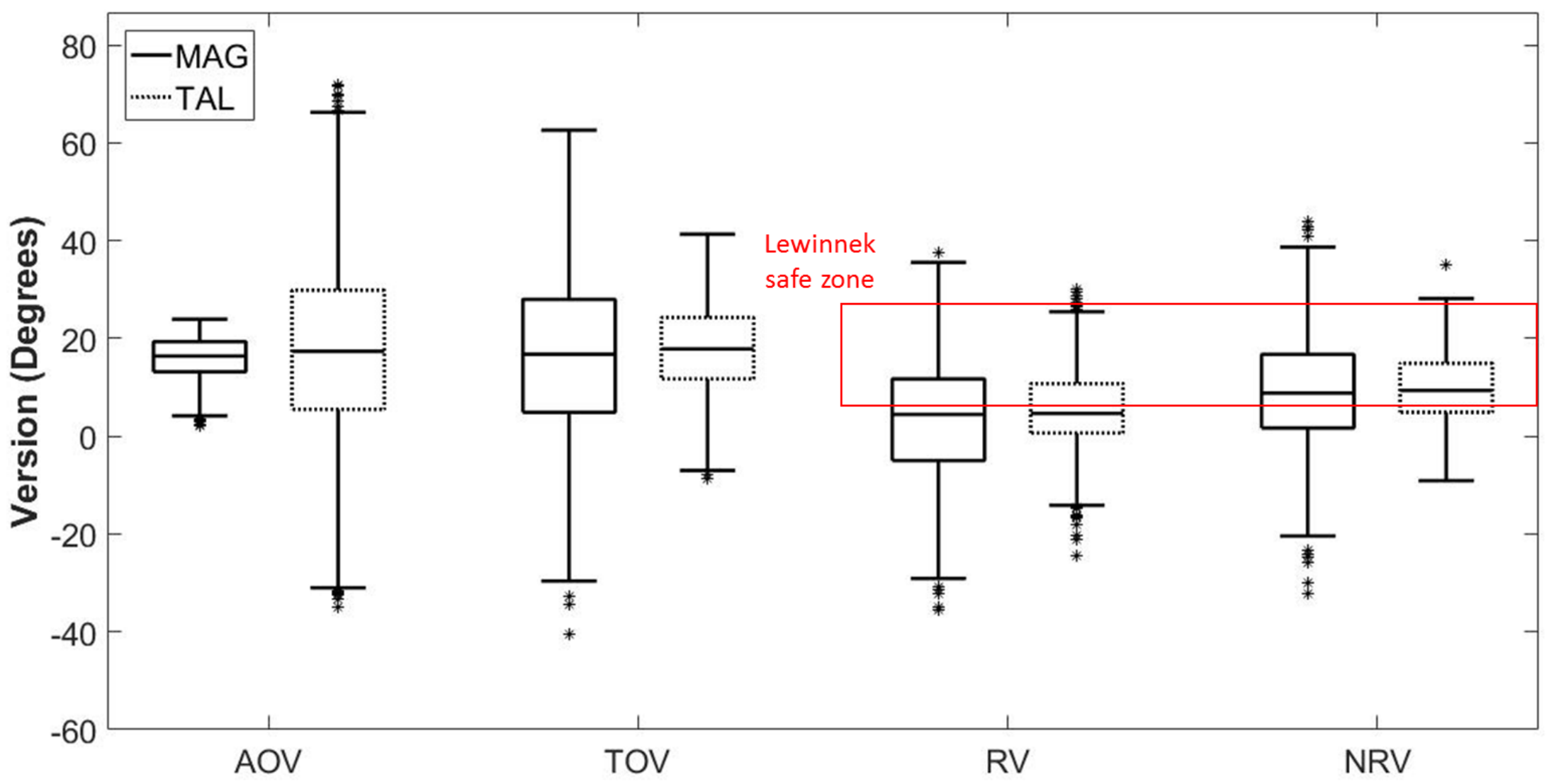

510 Figure 7: Measures of version. Statistical differences were observed between approaches $(\mathrm{p}<0.01)$. TAL method results in better control of TOV

511 when compared to MAG. Outliers (denoted by *) are defined as those points above Q3 + 1.5(Q3 - Q1) or below Q1 - 1.5(Q3 - Q1), where Q1 and 512 Q3 are the first and third quartiles, respectively. 


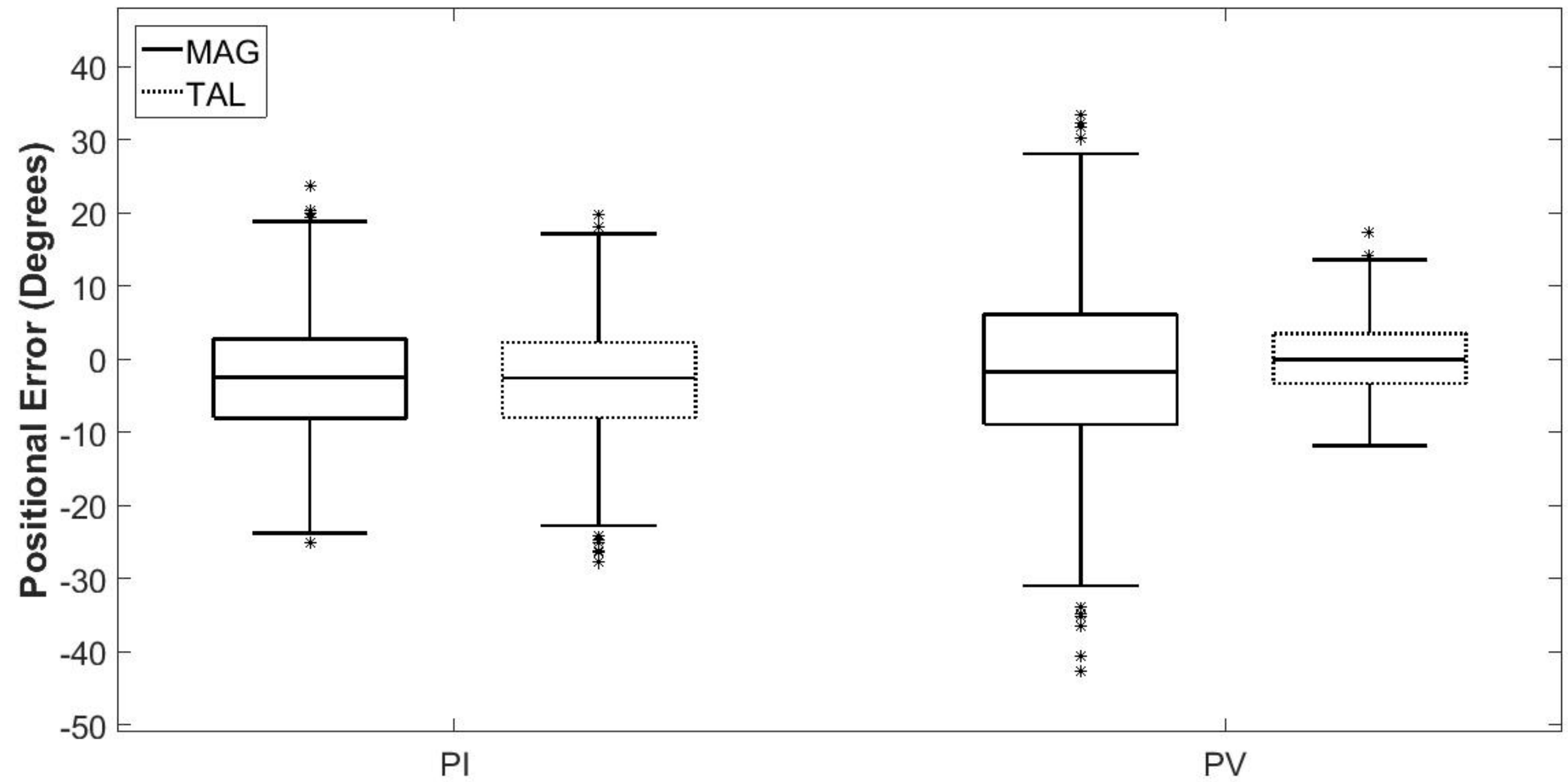

513 Figure 8: TAL reduces positional errors for version (PV) but not for inclination (PI). Outliers (denoted by *) are defined as those points above Q3

$514+1.5(\mathrm{Q} 3$ - Q1) or below Q1 - 1.5(Q3 - Q1), where Q1 and Q3 are the first and third quartiles, respectively. 